\title{
Rutilio Grande El nacimiento de una Iglesia nueva, salvadoreña y evangélica
}

\author{
Jon Sobrino \\ Centro de Reflexión Teológica \\ San Salvador
}

Hace treinta años murió asesinado el Padre Rutilio Grande. Su vida y su martirio simbolizan el nacimiento de una nueva Iglesia en El Salvador. Sobre esto queremos hacer unas breves reflexiones. Y lo hacemos porque, aunque obviamente es imposible repetir aquella Iglesia, necesitamos algunos elementos suyos fundamentales. Veámoslo.

En los años setenta la Iglesia salvadoreña ya había tomado un nuevo rumbo bajo el liderazgo del arzobispo Mons. Luis Chávez y González, y se notaba el influjo del Vaticano II y de Medellín. La expresión más clara de ello fue, por aquel entonces, el martirio de Rutilio y lo que lo motivó. Fue asesinado por defender a los campesinos de sus opresores y anunciarles la buena nueva de Dios: "una mesa común con manteles largos para todos". Rutilio fue como Jesús de Nazaret.

Este martirio no fue el punto final de la nueva Iglesia, lo cual bien pudiera haber sucedido, pues ante el asesinato de un sacerdote la prudencia pudiera haber aconsejado una marcha atrás. Ocurrió todo lo contrario. El asesinato de Rutilio se convirtió en punto de partida de una tradición eclesial. A lo largo de tres años - del 12 de marzo de 1977 al 24 de marzo de 1980 - esa tradición que comenzaba se fue enriqueciendo con una impresionante nube de testigos, con Monseñor Romero a la cabeza. Desencadenó una forma de ser Iglesia, históricamente nueva, salvadoreña, evangélica y popular. En el país no había ocurrido nada semejante en casi cinco siglos de cristianismo. 
Hoy las cosas han cambiado, evidentemente, en el país y en la Iglesia. Y no hay que olvidar que la Iglesia que surgió con Rutilio además fue perseguida inmisericordemente por los poderes de este mundo y dejó de ser apoyada por la institución eclesial. Paulatinamente se buscó sustituirla por una Iglesia con una misión poco encarnada y con pocos riesgos, y por una religiosidad de tipo más bien devocional.

Esto no quiere decir que no queda nada de aquella Iglesia. Sin mucho viento a favor, sigue viva en buen número de grupos y comunidades. Lo que pasa es que, como ocurre con el encuentro con Dios, a esa Iglesia "la encuentran los que la buscan", y no la encuentran los que no quieren encontrarla. Cada 24 de marzo esa Iglesia que comenzó con Rutilio se hace inocultable.

Y hay que mantenerla con vida, pues es necesaria. Debidamente historizada, como pedía Ellacuría, puede seguir generando una Iglesia viva en su interior y vivificante para el país. A continuación vamos a analizar algunos de sus elementos que nos parecen importantes y necesarios.

\section{Una Iglesia de talante recio}

La nueva Iglesia tuvo unos comienzos bien concretos, y para comprender lo que estaba en juego vayamos al evangelio de Marcos. Antes de decirnos en qué consistió la misión de Jesús, comienza con una precisión sobre el cuándo e, implícitamente, también sobre el por qué de esa misión: "después de que Juan fue preso, marchó Jesús a Galilea" (Mc 1, 14). Esto es más que una precisión temporal. Juan Bautista fue un profeta que denunciaba pecados y exigía conversión, y por ello fue encarcelado por Herodes y después asesinado. Pues bien, Marcos recalca que, precisamente en el momento en que Juan es puesto en prisión, Jesús de Nazaret comienza su misión.

Jesús proseguirá algo que en cierto modo ya estaba en marcha. Lo hará con hechos y palabras, diferentes a las de Juan, y anunciará la buena noticia del reino de Dios. Pero lo importante ahora es recordar que Jesús se entroncará en un movimiento que ya existía, aunque él lo configurará de manera propia y lo llevará a plenitud. Y correrá los mismos riesgos que el Bautista.

Sin caer en fáciles paralelismos, algo parecido puede decirse del origen de la nueva Iglesia salvadoreña. En Apopa Mario Bernal, sacerdote colombiano, con los campesinos llevaba a cabo una pastoral liberadora; por ello fue perseguido y expulsado del país. Expulsado Mario Bernal, Rutilio pronunció su profética homilía de Apopa, y un mes después era asesinado. Asesinado Rutilio, comenzó Mons. Romero. Y asesinado Monseñor - tras sus palabras "en nombre de Dios, cese la represión" - surgió en plenitud Ignacio Ellacuría.

En tres años se había generado en el país una tradición novedosa, por su contenido y por el modo de pasar de generación en generación. Por lo que toca al 
contenido, era específicamente martirial, y en un sentido preciso: el compromiso en favor del pueblo oprimido llevó a correr riesgos y a entregar la vida por su liberación. Por lo que toca a su transmisión, ésta no consistía en transmitir textos, sino en re-crear realidades. Este hecho martirial es lo que generó una nueva Iglesia.

A Rutilio, el protomártir, le siguieron muchos otros, no sólo los mencionados Romero y Ellacuría. Pronto fueron asesinados sacerdotes, el Padre Alfonso Navarro, Octavio Ortiz... Más tarde, religiosas, como Silvia, Ita y Maura; campesinos como Ticha y Polin... Y junto a estos mártires, a los que llamamos jesuánicos, se seguía consumando, implacable y recurrentemente, la muerte de un pueblo crucificado: en quince años el país quedó anegado en un mar de sangre, derramada inocente, indefensa e injustamente en El Sumpul, El Mozote, La Quesera...

Estos mártires, a los que llamamos el siervo doliente de Jahvé, el pueblo crucificado, no lo fueron por propia decisión. Son un factum brutum, cruel y recurrente. No se les puede ignorar por un mínimo de humanidad. Pero es también necesario recordarlos para comprender el nacimiento de la nueva Iglesia. Ellos son en definitiva los que desencadenaron el mayor amor de los mártires jesuánicos. Y ellos son los que, por estar en el centro de la Iglesia, junto con los mártires jesuánicos la configuraron como una nueva Iglesia.

Treinta años después, ya no hay martirios y asesinatos como los de entonces, evidentemente. Pero en El Salvador diez personas mueren diariamente de muerte violenta, y de diversas formas las mayorías continúan siendo el siervo sufriente de Jahvé. La pobreza sigue campante. La juventud sigue sin horizontes. La situación de las pandillas parte el corazón. No se ve fin a la injusticia y a la corrupción sobre todo en la administración de justicia y en los cuerpos policiales, a la mentira institucional en el aparato del estado y en los medios. Millones han tenido que abandonar el país, pues no tienen con qué vivir. Se les ha negado el suelo bajo sus pies.

La conclusión es que ante la situación de nuestro mundo no es anacronismo seguir recordando el origen martirial de la Iglesia salvadoreña. Hoy también la Iglesia debiera ser, en lo esencial, como aquélla: una Iglesia de hombres recios y mujeres valerosas. Es necesario y sólo bienes puede traer.

Ante todo, ayudará a superar la tentación - atractiva y masiva - de un cristianismo light, en sus formas más populares o en sus formas más solemnes e institucionales. La tentación de rehuír el conflicto con los poderosos y correr riesgos por ello. Ante quienes se vanaglorían de haber inventado una "liberación sin dolor", una redención light, Rutilio Grande les recuerda: "Es delito ser cristiano en nuestro país". Y lo sigue siendo para quien luche, no con mensajes abstractos, sino en serio, contra el pecado del mundo que sigue generando víctimas. $\mathrm{Y}$ 
aunque nos quede un poco lejos, no podemos olvidar a las 800.000 personas que viven en miserables champas en Kibera, Nairobi.

La reciedumbre no tiene por que ser temperamental. Mons. Romero, más aún Rutilio Grande, fueron de psicología débil, mientras que Ignacio Ellacuría era de carácter fuerte, y Maura era la expresión femenina de la ternura. Pero todos fueron recios. Recios en la profecía. Rutilio hablaba de "caínes" y Mons. Romero bramaba contra los que "convirtieron a Aguilares en una cárcel y en un lugar de tortura". Recios en la utopía. "Una mesa para todos, soñaba Rutilio. "Sobre estas ruinas brillará la gloria del Señor", gritó Monseñor Romero como un Isaías de nuestros días. "Hay que revertir la historia", dijo Ellacuría diez días antes de morir asesinado. Y recios en la entrega. "No vaya al Paisnal", le dijeron a Rutilo. "No vaya al hospitalito a celebrar la misa por la señora Sara", le dijeron a Monseñor. "No regrese a El Salvador", le dijeron a Ellacuría. Los tres fueron.

También hoy, si se deja a Dios ser Dios, sin manipularlo, sobreviene el destino de su Hijo bien amado y ninguna post-modernidad puede escamotear la dimensión agonista de la existencia cristiana. La tradición de Rutilio pide mantener en serio esta dimensión teologal y esta dimensión antropológica de una Iglesia que quiere ser cristiana. Y ciertamente su dimensión cristológica.

En el origen de una Iglesia cristiana está no cualquier hijo de Dios, sino Jesús de Nazaret, un crucificado, vivo y vivificante. Si las tradiciones reales de las Iglesias no se entroncan de alguna forma en tradiciones históricas actuales de cruz por amor, no habrá doctrina, ni exégesis ni hermenéutica que muevan a la fe en ese Jesús. Y la liturgia de semana santa será un intento de re-crear, imaginativamente, un recuerdo lejano.

Añadamos dos observaciones para terminar ese primer punto. Reciedumbre para nada se opone a ternura - "amar con ternura", se puede traducir la exigencia de Dios en Miqueas-, ni al gozo, ni al cuido de personas y de la naturaleza, que tanto nos piden hoy con toda razón. Los mártires que están en el origen de la nueva Iglesia salvadoreña fueron recios, cada cual con su temperamento, por una razón fundamental: por honradez con lo real, para estar a la altura de una realidad recia y para responder a ella.

Y una última reflexión personal. Creo yo que esa realidad martirial fundante pudo generar una tradición de Iglesia muy especial porque la realidad histórica y eclesial fue captada - existencialmente, no sólo epistemológicamente- de una manera específica. En el lenguaje que usábamos entonces, "hacernos cargo" de aquella Iglesia martirial movía, de por sí, como lo obvio que no necesita discernimiento, a "encargarse de ella", a ponerla a producir. Aquella Iglesia en sí misma daba fuerza para "cargar con ella", aunque no fuese más que por pudor. Y al dejarse ver, opthe, se nos apareció como don y gracia: esa Iglesia "cargaba con nosotros". En eso veo la raíz de que surgiesen — con naturalidad y en número 
sorprendente- hombres recios y valerosas mujeres. Hoy les echamos en falta. Entre otras cosas, porque ellos y ellas son quienes nos defienden del docetismo, el gnosticismo y lo light.

\section{Una Iglesia de eu-aggelion}

Hemos comenzado recordando la entrega por amor a los oprimidos, lo que configuró a la Iglesia con un talante de reciedumbre. Y nos hemos detenido en ello, pues es quizás lo más necesario en nuestros días. Transidos de ese talante recordaremos, muy brevemente y, a veces, sólo aduciendo citas que no necesitan comentario, algunos elementos de aquella Iglesia. El primero es la centralidad del euaggelion.

Treinta años después de la muerte y resurrección de Jesús, Marcos tuvo la genialidad de integrar, en forma de historia, los dichos y hechos de Jesús que le llevaron a la cruz. Aun cuando los cristianos ya celebraban liturgias y creían en la presencia del Señor en medio de ellos, volver atrás 30 ó 40 años fue una necesidad para que Jesús no quedara desfigurado o esfumado en el pasado. En ello estaba en juego la comprensión del cristianismo como seguimiento de Jesús y la posibilidad de saber a ciencia cierta a qué Jesus, real, no imaginado, había que seguir. Pero también estaba en juego algo quizás más profundo: la verdad de Dios y su buena noticia, el reino de Dios que predicaba Jesús y la realidad del mismo Jesús como eu-aggelion.

Entre nosotros, también se han ido recogiendo hechos y palabras de Rutilio Grande, su modo de ser cristiano y salvadoreño, su entrega por amor a los campesinos. A eso llamamos eu-aggelion. A continuación, recordamos simplemente algunas palabras suyas, ordenándolas según la estructura fundamental de la vida, praxis y destino de Rutilio. Fungen como símbolo de la Iglesia de aquellos tiempos.

La compasión hacia el pueblo. El misereor super turbas de Jesús en Rutilio se expresó sobre todo como compasión ante el sufrimiento de los campesinos. "Las chiltotas tienen un conacaste donde colgar sus nidos... Al pobre campesino no le dejan ni un conacaste, ni un puño de tierra para vivir o para que lo entierren". Esto sigue siendo el primer paso para la Iglesia de hoy. Y tiene que tomarlo en serio.

La profecía. Como consecuencia de la compasión, la profecía. "Ay de ustedes que se dicen católicos del diente al labio, y por dentro son inmundicia de maldad. Son Caínes que crucifican al Señor, cuando camina con el nombre de Toño, de Licha, del humilde trabajador del campo". Esta profecía sigue siendo absolutamente necesaria, pues sigue campante entre nosotros la injusticia, la corrupción, la impunidad... Producen pobreza, desempleo, violencia, muerte, tener que abandonar el país... Generan miedo, desesperanza... Y exigen una Iglesia de la denuncia para defender a las mayorías, víctimas de un sistema criminal. Es el eu-aggelion sub specie contrarii. 
La utopía. A pesar de todo, la utopía. "El mundo material es para todos sin fronteras. Luego una mesa común con manteles largos para todos, como esta Eucaristía. Cada uno con su taburete, y que para todos llegue la mesa, el mantel y el "conqué"". Es la Iglesia de la utopía, del reino, también aquí y ahora. "Un Padre común tenemos, luego todos somos hijos del mismo Padre, aunque hayamos nacido del vientre de distintas madres. Luegos todos somos hermanos". Es la Iglesia de la fraternidad, sin discriminación.

El mayor amor hasta el final. La coherencia. Rutilio decía que Jesús, "el hombre de Nazaret", como él le llamaba, si hoy partiese de Chalatenango, no llegaría con vida a San Salvador. Y ése fue su propio destino. El se convirtió en "el hombre de El Paisnal", el que, por amor a los campesinos, entregó su propia vida. Desde entonces, el evangelio de Rutilio está hecho de tres cosas: la buena noticia de una mesa común, su modo de ser, su cariño, respeto y agradecimiento a los campesinos, y su entrega por amarlos y defenderlos.

La Iglesia salvadoreña ha recibido este evangelio. Han sido transmitidas las palabras y los hechos de Rutilio. Pero es más fundamental que su vida y su muerte feron re-hechas y re-producidas muchas veces. Y es lo que hay que seguir reproduciendo: con reciedumbre anunciar un evangelio a los "campesinos" de hoy, pobres, jóvenes, emigrantes, mujeres... Con reciedumbre, decir la verdad a sus opresores sin rehuír conflictos. Con reciedumbre desvivirse para sanar a un mundo gravemente enfermo.

Sin eu-aggelion no hay Iglesia de Jesús. Lo que hay que recordar es que los destinatarios primarios del evangelio son los pobres. Los demás — hasta llegar a incluir a "todos" - tienen que participar de alguna manera, análogamente si se quiere, en el ser pobre de los pobres. Esa centralidad de los pobres, quienes pueden convocar a todos, fue también central en aquella Iglesia.

\section{Una Iglesia que busca la eficacia}

Rutilio Grande insistía en que hay que "poner patas al evangelio", ponerlo a producir. Esto sigue siendo necesario, y dos cosas importantes podemos aprender de la Iglesia de Rutilio: la necesidad de mediaciones y la convicción —a la vez indefensa y constatada - de la eficacia del evangelio.

Rutilio insistió en la necesidad de una buena formación, a la altura de los tiempos, y dio ejemplo de ello. Fue a Ecuador a prepararse en el IPLA, el de Proaño, en sus momentos más gloriosos de pastoral de liberación. Había que hacer uso de las "mediaciones", que se decía entonces, para encarnar con eficacia la verdad y el amor de Dios. Lo mismo pensaba Monseñor Romero, y ciertamente Ellacuría.

Esto sigue siendo una gran necesidad y es preciso que la Iglesia haga examen de conciencia sobre la formación de los cristianos en teología y en todos 
los saberes que configuran nuestro mundo, es decir, la creación de Dios. Y eso, tanto laicos y laicas, como sacerdotes y jerarcas. La acción pastoral de la Iglesia no debe quedar desvalida, dejada sólo a buenas intenciones. Ni debe quedar a merced de imposiciones y directrices lejanas. Y tampoco debe queda encerrada en una pastoral religiosa, que se distancia de los lugares y estructuras donde se decide la vida y la muerte de los seres humanos, sino hacerse presente en ellos. Y no sólo los laicos, sino también los clérigos.

Los enemigos intuyeron muy bien que Rutilio, los mártires, querían ser eficaces, querían cambiar lo más radicalmente posible la realidad. Por eso los asesinaron, y antes los difamaron a veces con paladina estupidez: "horizontalistas, marxistas, liberacionistas, medellinistas". Por eso hay que recordar que a la liberación les movía la fe en Dios y en su Cristo. Y no sólo eso: hay que recordar su convicción de que la fe y el evangelio tienen su propia eficacia, son fecundos. Y esta es otra constante - todavía más infrecuente - de la tradición de Rutilio: la convicción en la eficacia y fecundidad del evangelio para transformar personas y sociedades -que nada tiene que ver con el milagrismo reinante.

Si se me permite el lenguaje, sus enemigos les acusaban de "falta" de fe, pero lo que temían era su "exceso" de fe. Tenían fe en un misterio transcendente, fe difícil por lo tanto, pero real. Y una fe cristianamente entendida, no sólo como doctrina formulada, sino como convicción vivida. Dicho de otra forma, estaban convencidos de la "eficacia" de Dios, pero de un Dios "acercado" a los hombres. Es la transcendencia que se hizo trans-descendencia para llegar a ser con-descendencia. Ellacuría constató ese descenso salvador de Dios en sus conocidas palabras: "Con Monseñor Romero Dios pasó por El Salvador". Y Monseñor, en medio de destrozos, pudo decir: "Quien me diera que el fruto de esta predicación fuese ir a encontrarnos con Dios".

Hoy se insiste, con razón $-\mathrm{y}$ a veces nos lo recuerdan en tono acusador-. en la transcendencia y en la fe, pero no abunda la convicción de que ambas cosas son, también, fecundas. Para ser fructíferas, ni una ni otra dependen en definitiva de aceptar textos del magisterio, o catecismos, o escritos de los teólogos, todo ello bueno, cada cosa a su nivel. Son necesarios pero no suficientes, pues nada puede suplir la experiencia de la fuerza de Dios, tan frecuente aquellos años, en medio de y a través de amor y esperanza sin límites, de la santidad primordial del mundo de los pobres. Era la experiencia de un Emmanuel, un Dios con nosotros, en medio de nosotros. Rutilio lo formuló con gracejo inigualable. "Dios no está en las nubes acostado en una hamaca". Y sacó las consecuencias: "No trepen el evangelio a las nubes".

La tradición de Rutilio es una tradición de fe, recia y agradecida, y también convencida. Está transida del misterio profundo que rodea a Dios y de la esperanza histórica que ese misterio genera. Podrá parecer poca cosa —o fina retórica-, pero para comprender la tradición de Rutilio es fundamental tener 
en cuenta la fe en el misterio de Dios y en su fecundidad. Ellacuría terminó su último artículo de teología con estas palabras. "La fe cristiana historizada en hombres nuevos, que siguen anunciando firmemente, aunque siempre a oscuras, un futuro siempre mayor, porque más allá de los sucesivos futuros históricos se avizora el Dios salvador, el Dios liberador". Es una fe que nos hace avizorar a Dios y a un futuro salvador.

\section{Una Iglesia de los pobres}

Terminemos con algo esencial, es decir, que afecta literalmente a la esencia de la Iglesia, en la tradición de Rutilio: los pobres, los campesinos, "el pueblo". Los mártires hicieron la opción por los pobres, con naturalidad y sin debilitarla con la casuística, desconocida entonces, de si la opción era o no "preferencial", "no exclusiva ni excluyente". Pero además, en El Salvador, cada uno a su manera, dio un paso más, y surgió así una "Iglesia de los pobres". Evidentemente, con anterioridad lógica, ya había en la Iglesia fe en un Dios que ha pronunciado su palabra y ha enviado a su Hijo. Pero vieron en los pobres a los privilegiados de Dios. Por ello, aunque los pobres no son la totalidad, pueden configurar el todo de la Iglesia. Son, así, su principio de estructuración, organización y misión. Tienen el privilegio hermenéutico de ayudar a comprender la revelación y la tradición. Y ofrecen dirección y espíritu a la praxis y la pastoral.

La muerte de Rutilio fue el comienzo de una "Iglesia salvadoreña de mártires", pero, sin saberlo, también estaba llevando a plenitud el anhelo de Juan XXIII y de Medellín: una "Iglesia de los pobres". Esta Iglesia tomó cuerpo en las comunidades eclesiales de base, con problemas, pero con logros mayores. Crecieron porque sus hombres y mujeres tenían la Biblia en sus manos y empezaron a hacer uso del derecho humano, cristiano y religioso de comunicarse con Dios, en comunidad, sí, pero sin que nadie desde fuera les impusiese cómo debía ser esa relación, la más profunda del ser humano. Crecieron porque se comprometieron hasta el "mayor amor". Y crecieron porque fueron comunidad, comunión, eucaristía, mesa compartida.

Ellacuría dijo muy bien que esa Iglesia tiene su carta fundacional en las bienaventuranzas prometidas a "los pobres con espíritu". Y Monseñor Romero, en términos operativos, formuló espléndidamente su presupuesto teologal: "La gloria de Dios es que el pobre viva".

Hoy en día, ya casi ni se habla de "Iglesia de los pobres". Algunas iglesias se interesan por los pobres, pero otras no. Buscan eficazmente la relación con los poderes de este mundo, aunque fuese para hacer el bien. Y cuando hacen algún tipo de opción por los pobres, se cuidan muy mucho de introducirse en los conflictos que genera el defenderlos, aunque Puebla define a Dios no sólo como quien "ama" a los pobres, sino como quien los "defiende", con lo cual es inevitable algún enfrentamiento con los enemigos de los pobres. Y se cuidan de poner 
en peligro la paz al interior de la Iglesia, aunque de ello se desprenda muchas veces irrelevancia, tristeza y aun aburrimiento. $Y$ si se toleran sectas evangélicas da la impresión de que, al fin y al cabo, cualquier cosa parece ser mejor que las antiguas comunidades de base. Lo más peligroso es que quienes así piensan no dan señales de una esperanza verdaderamente evangélica: de los pobres viene salvación y humanización, y fuera de ellos con dificultad se encontrarán ambas cosas. No parece entrar en su ideario que también Jesús fue evangelizado por la viuda que echaba centavitos en el templo y por la mujer sirio-fenicia.

Ya hemos dicho que los mártires de la tradición de Rutilio fueron hombres y mujeres de Iglesia. Aceptaron con gozo su realidad de "pueblo de Dios", pero dieron una paso más, el más decisivo hasta el día de hoy: una "Iglesia de los pobres". En ella queda mejor reflejada la Iglesia de Jesús y es necesaria para salvar y humanizar a nuestro mundo. Tiene muchas cosas en contra, pero no partimos de cero. La Iglesia de los pobres tiene a su favor la tradición que empezó con Rutilio. Así lo dijo Monseñor Romero la noche de navidad de 1978:

"La Iglesia se predica desde los pobres, y no nos avergonzamos nunca de decir la Iglesia de los pobres, porque entre los pobres quiso poner Cristo su cátedra de redención".

Rutilio llevaba en su corazón a los pobres y veía su inmenso potencial. Y lo decía con estas palabras, tan típicamente suyas. "¿Les felicito, hermanos! Nos han dado una gran lección. Nos cuentan que en vez de ponerse a pelear con el hermano Pedro si la Virgen tuvo o no muchos hijos, si se puede comer gallina estrangulada o no, ustedes le ofrecieron su ayuda cuando le desalojaron. En su pobreza le han levantado el rancho y le ayudaron a trasladar sus tiliches".

Al recordar la Iglesia que nació con Rutilio, pudiéramos haber dicho muchas otras cosas. Aquí sólo nos hemos fijado en tres: una fe de hombres recios y de mujeres valerosas, una buena noticia de Dios y una Iglesia de los pobres. Siguen siendo muy necesarias, y eso es lo que hay que seguir pasando de generación en generación. En definitiva, lo que aprendimos de Rutilio es que hay que volver siempre a "Dios y a los pobres", "al hombre de Nazaret y a las víctimas".

Y quiero terminar con una reflexión que cada vez me parece más importante. Después del Vaticano II en muchos otros lugares han surgido tradiciones nuevas. En el tercer mundo muchas de ellas son tradiciones martiriales. En esta revista lo recordamos con frecuencia, teórica y testimonialmente. Y para ser fieles a nuestra tradición, no debemos recordar sólo a los mártires de El Salvador. Quedarnos en ellos sería injusto y empobrecedor $-\mathrm{y}$ sería ingratitud.

En el número anterior recordamos a Dietrich Bonhoeffer, teólogo y pastor de la Iglesia luterana, asesinado en 1945 a manos de los nazis. Y en el artículo 
que publicamos a continuación, recordamos a Monseñor Christophe Munzihirwa, S.J., arzobispo de Bukavu, República del Congo, de quien se cumplieron 10 años de su martirio el 26 de octubre de 1996. La causa de su asesinato fue la defensa de centenares de miles de refugiados, la denuncia de sus opresores y de la insensibilidad de las grandes potencias. Muchos en Africa le llaman hoy "el Romero del Congo".

Las tradiciones nacen y crecen, a veces languidecen o se adulteran. Pero hay que tomar en serio el hecho fundamental: en el tercer mundo han surgido muchas tradiciones de mártires en la línea de fe y justicia. Si mantenemos juntas todas ellas, diferentes según el espacio, el tiempo y las culturas, si mantenemos el modo de pasarlas de generación en generación, no sólo transmitiendo textos, sino re-produciendo realidades, entonces estaremos haciendo presente al Dios del que surgen y al que tienden todas estas tradiciones. Estaremos haciendo presente al Cristo de todos, pero especialmente al Cristo de Lázaro y de la mujer sirofenicia. Y con humildad estaremos ofreciendo salvación a Iglesias envejecidas y anquilosadas.

Entiéndasenos bien. No queremos más muertos, ni más mártires ni más pueblos crucificados. Queremos un nuevo cielo y una nueva tierra. Pero sí queremos mantener y entregar la tradición del mártir Rutilio Grande. Dos cosas especialmente: un amor sin condiciones y una fe con reciedumbre. Siguen siendo una bendición y una necesidad. 